Распределение растворенных и взвешенных форм тяжелых металлов в воде реки Сырдарьи (Южный Казахстан)

Б.М.Уралбеков ${ }^{1,2^{*}}$, Б.С. Сатыбалдиев ${ }^{1}$ D.D. Snow

${ }^{1}$ Центр физико-химических методов исследования и анализа, Казахский национальный университет

им. аль-Фараби, Алматы, Казахстан ${ }^{2} \mathrm{TOO}$ «EcoRadSM», Алматы, Казахстан

${ }^{3}$ Water Sciences Laboratory, University of Nebraska, Линкольн, США *E-mail: bulat.ural@gmail.com
Река Сырдарья является основным источником пресной воды Южного Казахстана, использующейся в сельском хозяйстве. Применение этой воды для орошения селькохозяйственных полей сказывается на изменении ее химического состава, что отражается в показателях класса качества воды, приведенных в информационных бюллетенях Министерства экологии, геологии и природных ресурсов Республики Казахстан. В настоящей работе изучено распределение взвешенных и растворенных форм тяжелых металлов в воде Сырдарьи на двух участках - верховье реки от Шардаринского водохранилища до моста «Коксарай» и низовье реки от г. Туркестана до п. Теренозек. Концентрациютяжелыхметаллов иметаллоидов определялиметодом масс-спектрометрии с индуктивно-связанной плазмой (ИСП МС Agilent 7500A, США). Общая концентрация групп металлов (V, Cu, Mn, Fe, Sr) превышает значения предельно-допустимых концентраций установленных для вод рыбохозяйственных водоемов. Оценена роль взвешенной формы в геохимической миграции ряда металлов в воде реки и показано, что взвешенная форма для большинства тяжелых металлов составляет значительную долю от общей концентрации металла. Наблюдается тенденция распределения взвешенных форм металлов аналогично значению мутности воды реки.

Ключевые слова: река Сырдарья; тяжелые металлы; растворенная форма; взвешенная форма; ПдК.

\section{Сырдария өзенінің суында (Оңтүстік Қазақстан)ауыр металдардың ерітілген және өлшенген түрлерінін таралуы}

Б.М.Уралбеков ${ }^{1,2^{*}}$, Б.С. Сатыбалдиев D.D. Snow

${ }^{1}$ Физика-химиялық зерттеу әдістері және талдау орталығы, әл-Фараби атындағы Қазақ ұлттық университеті, Алматы, Қазақстан ${ }^{2}$ «EcoRadSM» ЖШC Алматы, Қазақстан ${ }^{3}$ Water Sciences Laboratory, University of Nebraska, Линкольн, АҚШ *E-mail: bulat.ural@gmail.com
Сырдария өзені Оңтүстік Қазақстанның ауыл шаруашылығында пайдаланылатын тұщы судың негізгі көзі болып табылады. Бұл суды ауыл шаруашылығы алқаптарын суару үшін пайдалану оның химиялық құрамының өзгеруіне әсерін тигізеді, және бұл Қазақстан Республикасы экология, геология және табиғи ресурстар министрлігінің ақпараттық бюллетендерінде келтірілген су сапасы класының көрсеткіштерінде көрініс табады. Осы жұмыста Сырдария өзенінің суында, екі учаскеде - Шардара су қоймасынан «Көксарай» көпіріне дейінгі өзеннің жоғарғы сағасында және Түркістан қаласынан Тереңөзек ауылына дейінгі өзеннің төменгі сағасында ауыр металдардың қалқымалы және ерітілген түрлерінің таралуы зерттелді. Ауыр металдар мен металоидтардың концентрациясы массспектрометриялық әдіспен анықталды (ИСП MC Agilent 7500A, АҚШ). Металдар тобының (V, Cu, Mn, Fe, Sr) жалпы концентрациясы балық шаруашылығы бөгендерінің сулары үшін белгіленген ШРК мәнінен асады. Өзен суындағы бірқатар металдардың геохимиялық көші-қонындағы қалқымалы түрдің рөлі бағаланды және ауыр металдардың көпшілігі үшін қалқымалы түр металдың жалпы концентрациясының едәуір бөлігін құрайтындығы көрсетілген. Өзен суы лайлылығының мәніне ұқсас металдардың қалқымалы түрлерінің таралу үрдісі байқалады.

Түйін сөздер: Сырдария өзені; ауыр металдар; еріген түрі; қалқыма түрі; ШРК.

\section{Distribution of dissolved and suspended forms of heavy metals in the water of the Syr Darya, South Kazakhstan}

B.M. Uralbekov ${ }^{1,2}$, B.S. Satybaldiyev ${ }^{1}$, D.D. Snow

${ }^{1}$ Center of Physical-Chemical Methods of Research and Analysis, al-Farabi Kazakh National University, Almaty, Kazakhstan 'LLP «EcoRadSM», Almaty, Kazakhstan ${ }^{3}$ Water Sciences Laboratory, University of Nebraska, Lincoln, NE 68583, USA *E-mail: bulat.ural@gmail.com
The water of the Syr Darya is the main source of fresh water in South Kazakhstan and heavily used for agriculture. The use water from the Syr Darya for irrigation of agricultural fields affects its chemical composition and is reflected in the water quality class provided in the bulletins of the Ministry of Ecology, Geology and Natural Resources of the Republic of Kazakhstan. In the present work, the distribution of suspended and dissolved forms of heavy metals in the water of the Syr Darya has been studied in two areas - the upper reaches of the river from the Shardara reservoir to the «Koksaray» bridge and the lower reaches of the river from Turkestan to Terenozek. Concentrations of heavy metals and metalloids were determined by inductively coupled plasma mass spectrometry (ICP-MS, Agilent 7500A, United States) and compared to these recommended levels. Total concentrations of several metals (V, Cu, Mn, Fe, Sr) exceed the Maximum Permissible Concentrations established for waters of fishery reservoirs. The role of the suspended form in the geochemical migration of a number of metals in the water of the Syr Darya River is estimated and it was shown that this form is a significant fraction of the total metal concentration. The distribution of suspended forms of metals correlates to the turbidity of the water of the Syr Darya.

Keywords: the Syr Darya river; heavy metals; dissolved form; suspended form; MPC. 


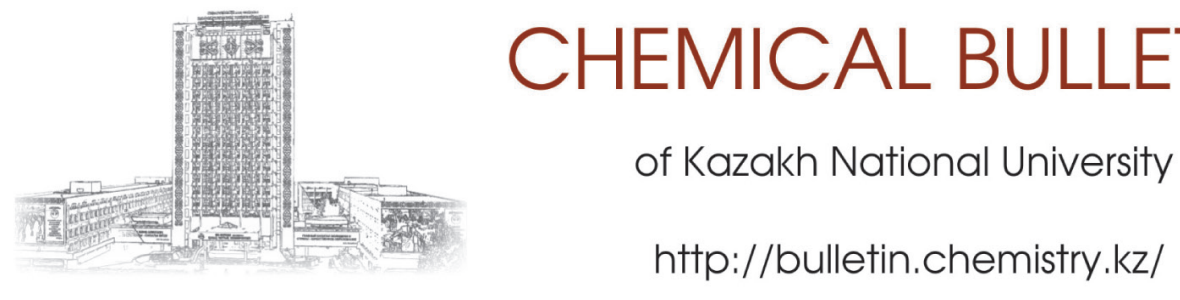

УдК 550.424

https://doi.org/10.15328/cb1016

\title{
Распределение растворенных и взвешенных форм тяжелых металлов в воде реки Сырдарьи (Южный Казахстан)
}

\author{
Б.М. Уралбеков ${ }^{1,2 *}$, Б.C. Сатыбалдиев ${ }^{1}$, D.D. Snow ${ }^{3}$ (1) \\ ${ }^{1} Ц$ ентр физико-химических методов исследования и анализа, Казахский национальный университет им. Аль-Фараби, \\ 050000, пр. Аль-Фараби, 71, Алматы, Казахстан \\ ${ }^{2} \mathrm{TOO}$ «EcoRadSM», 050040, ул. Толе би 96А, Алматы, Казахстан \\ ${ }^{3}$ Water Sciences Laboratory, University of Nebraska, 1840 N. 37th St, Линкольн, США \\ *E-mail: bulat.ural@gmail.com
}

\section{1. Введение}

Бассейн реки Сырдарьи включает многочисленные притоки, водохранилища, а также системы орошения и каналы. Программы по увеличению производительности сельского хозяйства в бассейне реки привели куменьшению расхода воды реки; в свою очередь, снижение уровня воды в реке или водохранилищах может привести к повы-шению концентрации загрязняющих веществ. Учитывая, что технологии орошения земель незначительно улучшились за последние годы, значительный объем возвратных вод с полей, насыщенных удобрениями и пестицидами, способствует поступлению в воду реки различных загрязняющих веществ, в том числе и тяжелых металлов.

В настоящее время сведения по геохимическому поведению тяжелых металлов в бассейне Сырдарьи скудны, что связано и с проблемами аналитического определения элементов в следовых количествах. В основном приводятся сведения по изменению расхода воды, минерализации и основных ионов [1-3], а также по содержанию групп тяжелых металлов [4,5]. Применение воды реки Сырдарьи для орошения полей сказывается на изменении химического состава воды, что отражается в показателях индекса загрязнения воды, приведенных в ежеквартальных информационных бюллетенях Министерства экологии, геологии и природных ресурсов РК [6]. Из этих бюллетеней следует, что для воды Сырдарьи (Туркестанская и Кызылординская области) характерен относительно высокий класс качества (4-й), что означает необходимость интенсивной водоподготовки перед использованием этой воды в целях хозяйственного/ питьевого водоснабжения [6]. Кроме того, наблюдается превышение ПДК по ряду показателей, включая содержание тяжелых металлов (железо, медь).

Целью работы является изучение распределения тяжелых металлов и некоторых металлоидов во взвешенных и растворенных формах в воде реки Сырдарьи (Южный Казахстан). Приводятся данные по содержанию тяжелых металлов в воде реки; пробы отобраны на двух участках - верховье реки от Шардаринского водохранилища до моста «Коксарай» и низовье реки от г. Туркестана до п. Теренозек. Эти отрезки бассейна реки выбраны ввиду наличия источников загрязнения тяжелыми металлами (сельскохозяйственные угодья, рудники), которые могут оказывать негативное воздействие как на человека, так и на окружающую среду.

\section{2. Эксперимент}

Материалы для исследования - пробы воды реки Сырдарьи, отобранные в мае 2013 году в низовье реки и в июне 2015 году в верховье реки. Пробы отбирались согласно ГОСТу [7]. Для оценки содержания тяжелых металлов во взвешенной форме пробы фильтровались через фильтры с диаметром пор 0,45 мкм. Пробы воды подкислялись концентрированной азотной кислотой (ultra pure) до значения pH 1-2. Географические координаты мест отбора проб определялись с помощью спутникового навигационного прибора Garmin GPS 12XL (таблица 1). Карты с точками отбора в низовье реки приведены в работе [8], в верховье реки - в работе [9]. В местах отбора проб определяли $\mathrm{pH}$, содержания кислорода, электропроводность с помощью полевой лаборатории типа НАCH (Hach Corporation, Loveland, США). 
Таблица 1 - Географические координаты мест отбора проб на реке Сырдарья

\begin{tabular}{|c|c|c|}
\hline \multirow{2}{*}{ Место отбора } & \multicolumn{2}{|c|}{ Географические координаты } \\
\hline & Широта & Долгота \\
\hline $\begin{array}{c}\text { Водохранилище } \\
\text { «Шардара» }\end{array}$ & $N 41^{\circ} 10^{\prime} 24,0^{\prime \prime}$ & E $067^{\circ} 55 / 59,1^{\prime \prime}$ \\
\hline Ниже вдхр. «Шардара» & $N 41^{\circ} 15 / 55,1^{\prime \prime}$ & $\mathrm{E} 067^{\circ} 57 / 14,7^{\prime \prime}$ \\
\hline п. «Сюткент» & $N 41^{0} 55 / 49,8^{\prime \prime}$ & $\mathrm{E} 066^{\circ} 42^{\prime} 34,7^{\prime \prime}$ \\
\hline Мост «Арыс» & $N 42^{\circ} 13 / 16,4^{\prime \prime}$ & E $068^{\circ} 14 / 56,9^{\prime \prime}$ \\
\hline Мост «Коксарай» & $N 42^{\circ} 36 / 56,2^{\prime \prime}$ & $\mathrm{E} 068^{\circ} 13^{\prime} 07,03^{\prime /}$ \\
\hline г. Туркестан & $N 43^{\circ} 0940,4^{\prime \prime}$ & E $067^{\circ} 50 / 59,6^{\prime \prime}$ \\
\hline п. Бесарык & $N 43^{\circ} 32^{\prime} 43,5^{\prime \prime}$ & $\mathrm{E} 067^{\circ} 30^{\prime} 23,7^{\prime \prime}$ \\
\hline п. Первомайка & $N 43^{\circ} 52^{\prime} 27,0^{\prime \prime}$ & $\mathrm{E} 067^{\circ} 11^{\prime} 50,3^{\prime \prime}$ \\
\hline п. Томенарык & $N 43^{\circ} 52^{\prime} 27,0^{\prime \prime}$ & $\mathrm{E} 067^{\circ} 01^{\prime} 20,2^{\prime \prime}$ \\
\hline мост п. Актам & $N 43^{\circ}, 57 / 02,4^{\prime \prime}$ & $\mathrm{E} 066^{\circ} 42^{\prime} 34,7^{\prime \prime}$ \\
\hline п. Кызылкайын & $\mathrm{N} 44^{\circ} 08^{\prime} 36,8^{\prime \prime}$ & E $066^{\circ} 25 / 34,1^{\prime \prime}$ \\
\hline Выше п. Байгекум & $N 44^{\circ} 17^{\prime} 43,9^{\prime \prime}$ & E $066^{\circ} 30^{\prime} 51,1^{\prime \prime}$ \\
\hline п. Байгекум & $N 44^{\circ} 18 / 23,2^{\prime \prime}$ & $\mathrm{E} 066^{\circ} 29^{\prime} 08,4^{\prime \prime}$ \\
\hline п. Тартогай & $N 44^{\circ} 24^{\prime} 49,3^{\prime /}$ & E $066^{\circ} 12 / 58,2^{\prime \prime}$ \\
\hline п. Берказан & $N 44^{\circ} 45 / 10,2^{\prime \prime}$ & $\mathrm{E} 065^{\circ} 44 / 51,2^{\prime \prime}$ \\
\hline п. Караозек & $N 44^{\circ} 58 / 52,9^{\prime \prime}$ & $\mathrm{E} 065^{\circ} 18 / 50,8^{\prime \prime}$ \\
\hline п. Теренозек & $N 45^{\circ} 01^{\prime} 21,5^{\prime \prime}$ & $\mathrm{E} 064^{\circ} 59 / 07, \mathrm{O}^{\prime \prime}$ \\
\hline
\end{tabular}

Концентрацию тяжелых металлов и металлоидов определяли масс-спектрометрическим методом на основе индуктивно-связанной плазмы (ИСП МС Agilent 7500A, США). Правильность результатов контролировалась использованием ГСО и международных стандартных образцов ТМ-27.3 и ТМ 64.2 (Канада).

\section{3. Результаты и обсуждение}

Концентрация растворенного кислорода в воде Сырдарьи на изучаемых участках составляет 6,3-13,0 мг/л. Вода реки и Шардаринского водохранилища характеризуется слабощелочной реакцией среды (рН 8,0-8,5). Электропроводность воды реки изменяется незначительно (1335-1687 мкСм/см) вниз по течению, что свидетельствует о незначительном увеличении концентрации главных ионов на рассматриваемом отрезке реки.

Содержание тяжелых металлов и металлоидов в пробах воды приведено в таблице 2. Общая концентрация групп металлов (V, Cu, Mn, Fe, Sr) превышает пдК для вод рыбохозяйственных водоемов [10]. Например, для ванадия это в среднем 1,8 ПДК, для марганца - 1,5 ПдК, для железа - 4 ПДК, и для меди - 6 ПДК. Сопоставление общих концентраций элементов с соответствующими значениями пдК следует проводить с осторожностью из-за особенностей геохимической миграции элементов. В частности, необходимо оценить долю элементов, мигрирующих во взвешенных формах, которая может быть легко удалена в процессе водоподготовки.

Из таблицы 2 видно, что взвешенная форма для большинства тяжелых металлов составляет значительную долю от общей концентрации металла. На рисунке 1 представлено распределение соотношения растворенной и взвешенной форм марганца вдоль течения реки. Видно, что марганец преимущественно сосредоточен во взвешенной форме (30,0-97,5\%). Наименьшее значение доли взвешенной формы марганца было обнаружено в районе п. Байгекум, что связано с низким содержанием взвеси в точке отбора воды (мутность 7,1 FNU).

Роль взвешенной формы в геохимической миграции рассматриваемых металлов можно показать на примере

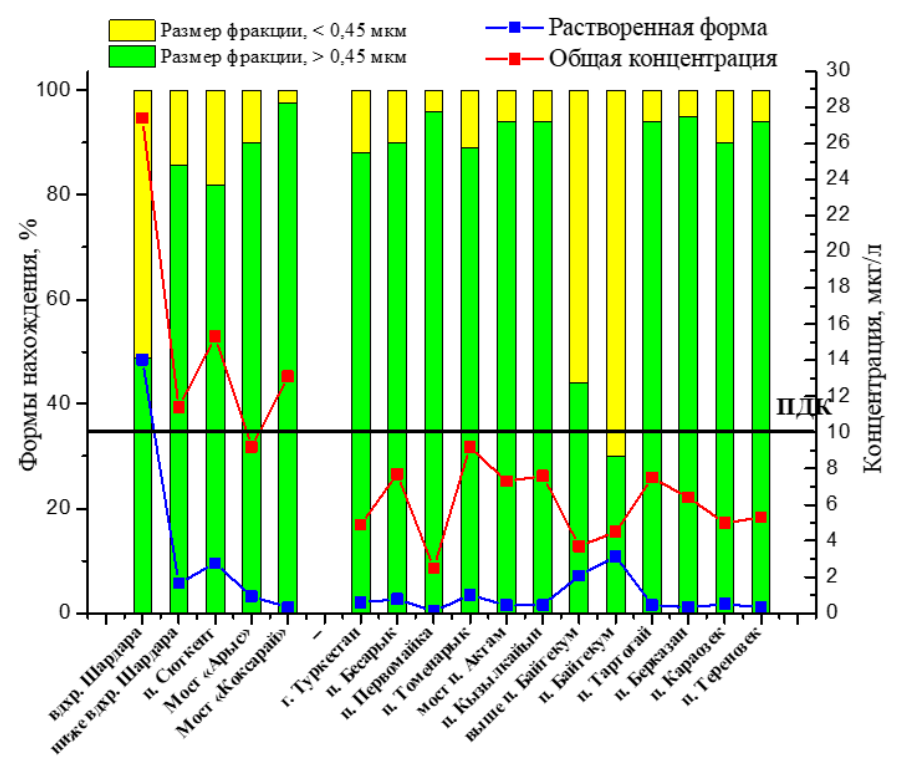

Рисунок 1 - Распределение растворенной и взвешенной форм марганца в воде реки Сырдарьи 
ванадия (рисунок 2) и марганца (рисунок 1). Общая концентрация ванадия (включая растворенные и взвешенные формы) превышает ПдК на всем протяжении исследуемого участка, тогда как его концентрация в растворенной форме находится ниже или на уровне соответствующей ПДК (для проб, отобранных в низовье реки). Для марганца концентрация его в растворенной форме превышает пДК (в 2,4 раза) только в одной точке отбора - в воде Шардаринского водохранилища. Для групп металлов $\left(\mathrm{Fe}_{\text {взв. }}, \mathrm{Mn}_{\text {взв. }}, \mathrm{Cu}_{\text {взв. }}, \mathrm{Zn}_{\text {взв. }}, \mathrm{Pb}_{\text {взв. }}, \mathrm{Ni}_{\text {взв. }}\right)$, в целом, наблюдается тенденция распределения взвешенных форм металлов аналогично содержанию взвеси в воде, которая оценена в этой работе по значению мутности воды.
Таким образом, большая часть металлов, находящихся во взвешенном состоянии, может быть легко у далена в процессе водоподготовки - методами очистки воды, включая методы фильтрации и отстаивания.

Группа металлов (молибден, стронций, уран) находится предпочтительно в растворенных формах (фракция с размером частиц < 0,45 мкм), что обусловлено высокой геохимической подвижностью молибдена [12] и стронция, а также способностью урана к комплексобразованию. В частности, уран в природных водах сульфатно-карбонатного типа образует прочные карбонатные комплексные соединения [11].

Таблица 2 - Общая концентрация и содержание взвешенных форм (>0,45 мкм) тяжелых металлов и металлоидов в воде реки Сырдарьи

\begin{tabular}{|c|c|c|c|c|c|}
\hline \multirow[b]{2}{*}{ Элемент } & \multicolumn{4}{|c|}{ Концентрация - диапазон (мин. - макс.) и средняя, мкг/л } & \multirow{2}{*}{$\begin{array}{c}\text { пдк, } \\
\text { мкг/л } \\
{[10]}\end{array}$} \\
\hline & $\begin{array}{c}\text { Верховье реки: } \\
\text { участок водохранилища Сырдарья - } \\
\text { мост «Коксарай» }\end{array}$ & $\begin{array}{c}\%, \\
>0,45 \text { мкм }\end{array}$ & $\begin{array}{c}\text { Низовье реки: } \\
\text { участок г. Туркестан - п. Теренозек } \\
{[11]}\end{array}$ & $\begin{array}{c}\%, \\
>0,45 \text { мкм }\end{array}$ & \\
\hline $\mathrm{v}$ & $\begin{array}{c}1,66-1,89 \\
1,79\end{array}$ & $0-39,8$ & $\begin{array}{c}0,96-2,32 \\
1,7\end{array}$ & $7-70$ & 1 \\
\hline $\mathrm{Cr}$ & $\begin{array}{c}0,16-0,31 \\
0,24\end{array}$ & $\sim 100$ & $\begin{array}{c}1,9-8,2 \\
5,5\end{array}$ & $0-73$ & \\
\hline $\mathrm{Mn}$ & $\begin{array}{c}9,2-27,4 \\
15,3\end{array}$ & $48,8-97,5$ & $\begin{array}{c}2,5-9,2 \\
6,0\end{array}$ & $30-96$ & 10 \\
\hline $\mathrm{Fe}$ & $\begin{array}{c}375,7-487,6 \\
422,7\end{array}$ & $34,7-60,9$ & н. д. & & 100 \\
\hline Co & $\begin{array}{c}0,20-0,3 \\
20,25\end{array}$ & $46,5-60,2$ & $\begin{array}{c}0,1-5,1 \\
2,1\end{array}$ & $0-93$ & \\
\hline $\mathrm{Ni}$ & $\begin{array}{c}1,16-1,52 \\
1,29\end{array}$ & $23,9-50,1$ & $\begin{array}{c}2,3-6,8 \\
3,8\end{array}$ & $8-81$ & 10 \\
\hline $\mathrm{Cu}$ & $\begin{array}{c}5,29-6,69 \\
5,93\end{array}$ & $18,5-25,7$ & $\begin{array}{c}0,7-2,6 \\
1,4\end{array}$ & $0-77$ & $1^{*}$ \\
\hline $\mathrm{Zn}$ & $\begin{array}{c}2,28-3,72 \\
2,67\end{array}$ & $62,4-82,7$ & $\begin{array}{c}3,9-48,7 \\
21,8\end{array}$ & $0-65$ & 10 \\
\hline As & $\begin{array}{c}1,0-1,6 \\
1,36\end{array}$ & $23,7-39,5$ & $\begin{array}{c}1,1-1,6 \\
1,3\end{array}$ & $0-56$ & 50 \\
\hline Se & $\begin{array}{c}1,3-1,4 \\
1,36\end{array}$ & $14,0-28,5$ & н.д. & & 2 \\
\hline $\mathrm{Sr}$ & $\begin{array}{c}1833-2054 \\
1970\end{array}$ & $2,9-13,2$ & н. д. & & 400 \\
\hline $\mathrm{Ba}$ & $\begin{array}{c}45,0-46,7 \\
45,6\end{array}$ & $1,2-18,1$ & $\begin{array}{c}32,3-67,3 \\
54,2\end{array}$ & $0-40$ & 740 \\
\hline $\mathrm{Pb}$ & $\begin{array}{c}1-3,5 \\
1,8\end{array}$ & $\sim 100$ & $\begin{array}{c}0,2-3,3 \\
1,5\end{array}$ & $0-93$ & 6 \\
\hline U & $\begin{array}{c}12,8-13,9 \\
13,4\end{array}$ & $\sim 0$ & $\begin{array}{c}14,67-17,37 \\
16,7\end{array}$ & $0-1,64$ & 1 \\
\hline Mo & н.д. & н.д. & $\begin{array}{c}6,3-7,9 \\
7,4\end{array}$ & $0-9$ & \\
\hline
\end{tabular}

Примечания:

ПДК - предельно-допустимая концентрация;

$\%,>0,45$ - доля взвешенных частиц от общей концентрации, в процентах;

н. д. - данные отсутствуют;

*- к природному естественному фону (в этой работе естественный фон принят равным нулю). 


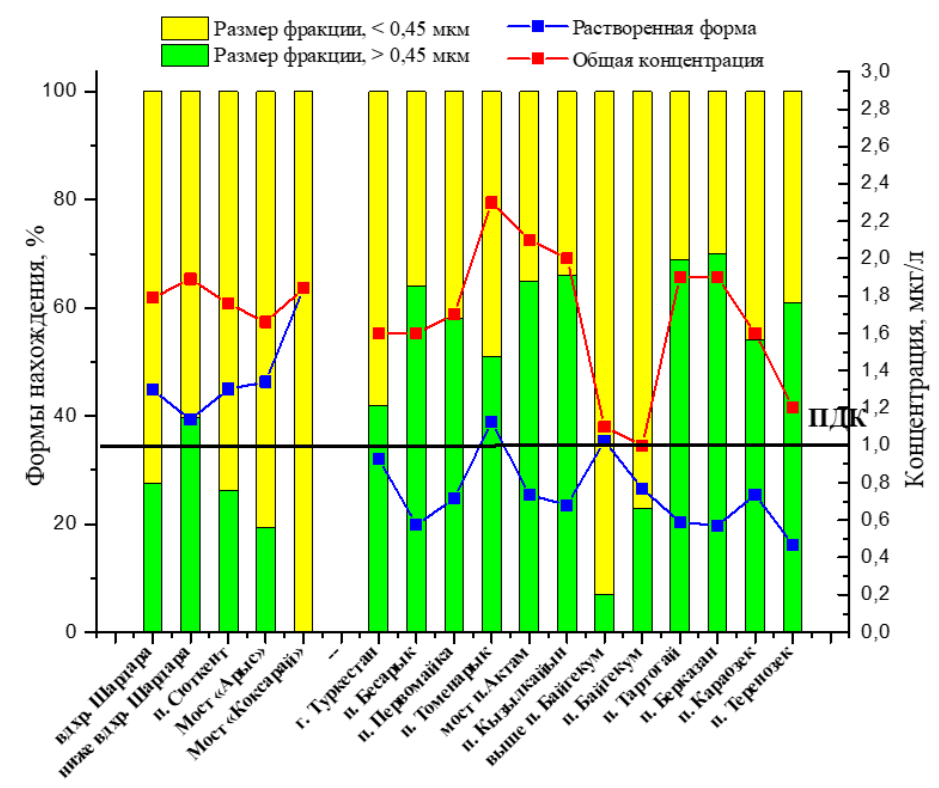

Рисунок 2 - Распределение растворенной и взвешенной форм ванадия в воде реки Сырдарьи

\section{4. Заключение}

Изучено распределение взвешенных и растворенных форм тяжелых металлов в воде реки Сырдарьи на двух участках - верховье реки от Шардаринского водохранилища до моста «Коксарай» и низовье реки от г. Туркестана до п. Теренозек. Для групп металлов (Fe, Mn, $\mathrm{Cu}$, $\mathrm{Zn}, \mathrm{Pb}, \mathrm{Ni})$ наблюдается тенденция распределения взвешенных форм металлов аналогично содержанию взвеси в воде, которая оценена в этой работе по значению мутности воды. Вода реки Сырдарьи может быть очищена от большей части тяжелых металлов (во взвешенном состоянии) во время водоподготовки простыми методами очистки воды, включая методы фильтрации и отстаивания.

\section{Благодарности}

Работа выполнена в рамках проекта АР08857167 грантового финансирования Комитета науки Министерства образования и науки Республики Казахстан

\section{Литература}

1 English M.J., Solomon K.H., Hoffman G.J. A paradigm shift in irrigation management //Journal of irrigation and drainage engineering. - 2002. - Vol.128, Is.5. - P.267-277.

2 Pimentel D., Houser J., Preiss E., White O., Fang H., Mesnick L., Barsky T., Tariche S., Schreck J., Alpert S. Water resources: agriculture, the environment, and society // BioScience. - 1997. - Vol.47, Is.2. - P.97-106.

3 Zhang W., Ma L., Abuduwaili J., Ge Y., Issanova G., Saparov G. Hydrochemical characteristics and irrigation suitability of surface water in the Syr Darya River, Kazakhstan // Environmental monitoring and assessment. - 2019. - Vol.191, Is.9. - ID572.

4 Krupa E.G., Barinova S.S., Amirgaliyev N.A., Issenova G., Kozhabayeva G. Statistical approach to estimate the anthropogenic sources of potentially toxic elements on the Shardara Reservoir (Kazakhstan) // MOJ Ecology \& Environmental Sciences. - 2017. Vol.2, Is.1. - P.8-14.

5 Rzymski P., Klimaszyk P., Niedzielski P., Marszelewski W., Borowiak D., Nowiński K., Baikenzheyeva A., Kurmanbayev R., Aladin N. Pollution with trace elements and rare-earth metals in the lower course of Syr Darya River and Small Aral Sea, Kazakhstan // Chemosphere. - 2019. - Vol.234. - P.81-88.

6 Веб-сайт Казгидромет. Ежемесячный информационный бюллетень о состоянии окружающей среды. https:// kazhydromet.kz/ru/ecology/ezhemesyachnyy-informacionnyy-byulleten-o-sostoyanii-okruzhayuschey-sredy

7 ГОСт 17.1.5.05-85. Охрана природы. Гидросфера. Общие требования к отбору проб поверхностных и морских вод, льда и атмосферных осадков. - Введ.1986-01-07. - М.: Изд-во стандартов, 1987.

8 Satybaldiyev B., Tuovinen H., Uralbekov B., Lehto J., Burkitbayev M. Heavy metals and natural radionuclides in the water of 
Syr Darya River, Kazakhstan. In: Merkel B., Arab A. (eds) Uranium - Past and Future Challenges. - Springer, Cham, 2015. - P.155-160. 9 Snow D. D., Chakraborty P., Uralbekov B., Satybaldiev B., Sallach J. B., Hampton L.T., Jeffries M., Kolok A.S., Bartelt-Hunt S.B. Legacy and current pesticide residues in Syr Darya, Kazakhstan: Contamination status, seasonal variation and preliminary ecological risk assessment // Water research. - 2020. - Vol.184. - ID116141.

10 Обобщенный перечень предельно допустимых концентраций (ПдК) и ориентировочно безопасных уровней воздействия (ОБУВ) вредных веществ для воды рыбохозяйственных водоемов. - М.: Минрыбхоз СССР, 1990. - 49 с.

11 Буркитбаев М.М., Уралбеков Б.М., Тузова Т.В. Неравновесный уран как естественный индикатор процессов в водно экологических системах Центральной Азии. - Алматы: КазНУ, 2017. - 160 с.

12 Труфанов А. И. Аномалии молибдена в природных водах ландшафтных районов южной и средней тайги // Бюллетень Оренбургского научного центра УрО РАН. - 2011. - №2.

\section{References}

1 English MJ, Solomon KH, Hoffman GJ (2002) J Irrig Drain Eng 128:267-277. https://doi.org/10.1061/(ASCE)07339437(2002)128:5(267)

2 Pimentel D, Houser J, Preiss E, White O, Fang H, Mesnick L, Barsky T, Tariche S, Schreck J, Alpert S (1997) BioSci 47:97-106. https://doi.org/10.2307/1313020

3 Zhang W, Ma L, Abuduwaili J, Ge Ylssanova G, Saparov G (2019) Environ Monit Assess 191:572. https://doi.org/10.1007/s10661019-7713-8

4 Krupa EG, Barinova SS, Amirgaliyev NA, Issenova G, Kozhabayeva G (2017) MOJ Eco Environ Sci 2(1):8-14. https://doi. org/10.15406/mojes.2017.02.00012

5 Rzymski P, Klimaszyk P, Niedzielski P, Marszelewski W, Borowiak D, Nowiński K, Baikenzheyeva A, Kurmanbayev R, Aladin N (2019) Chemosphere 234:81-88. https://doi.org/10.1016/j.chemosphere.2019.06.036

6 Kazhydromet website. Monthly newsletter on the state of the environment [Yezhemesyachnyy informatsionnyy byulleten' o sostoyanii okruzhayushchey sredy]. https://kazhydromet.kz/ru/ecology/ezhemesyachnyy-informacionnyy-byulleten-o-sostoyaniiokruzhayuschey-sredy. (In Russian)

7 GOST 17.1.5.05-85. Protection of Nature. Hydrosphere. General requirements for sampling surface and sea waters, ice and atmospheric precipitation [Okhrana prirody. Gidrosfera. Obshchiye trebovaniya k otboru prob poverkhnostnykh i morskikh vod, l'da i atmosfernykh osadkov]. Moscow, USSR, 1987. (In Russian)

8 Satybaldiyev B, Tuovinen H, Uralbekov B, Lehto J, Burkitbayev M (2015) Heavy metals and natural radionuclides in the water of Syr Darya River, Kazakhstan. In: Merkel B., Arab A. (eds) Uranium - Past and Future Challenges. Springer, Cham. P.155-160. https:// doi.org/10.1007/978-3-319-11059-2_18

9 Snow DD, Chakraborty P, Uralbekov B, Satybaldiev B, Sallach JB, Hampton LT, Jeffries M, Kolok AS, Bartelt-Hunt SB (2020) Water Res 184:116141. https://doi.org/10.1016/j.watres.2020.116141

10 A generalized list of maximum permissible concentrations (MPC) and tentatively safe exposure levels (TSEL) of harmful substances for the water of fishery reservoirs [Obobshchennyy perechen' predel'no dopustimykh kontsentratsiy (PDK) $\mathrm{i}$ oriyentirovochno bezopasnykh urovney vozdeystviya (OBUV) vrednykh veshchestv dlya vody rybokhozyaystvennykh vodoyemov]. Moscow, USSR, 1990. (In Russian)

11 Burkitbayev MM, Uralbekov BM, Tuzova TV (2017) Non-equilibrium uranium as a natural indicator of processes in the waterecological systems of Central Asia [Neravnovesnyi uran kak estestvennyi indikator processov v vodno-ecologicheskih sistemah Central’noy Azii]. Kazakh University, Almaty, Kazakhstan. (In Russian). ISBN 978-601-04-2923-9

12 Trufanov AI (2011) Bulletin of the Orenburg Scientific Center of the Ural Branch of the Russian Academy of Sciences [Byulleten' Orenburgskogo nauchnogo tsentra UrO RAN] 2. (In Russian) 